\title{
MALE PHYSICAL RISK TAKING IN A VIRTUAL ENVIRONMENT
}

\author{
WILLEM E. FrankENHUIS ${ }^{1, *}$, RON DOTSCH ${ }^{2}$, JOHAN C. KARREMANS ${ }^{2}$, \\ DANIËL H. J. WigBOLDUS ${ }^{2}$
}

${ }^{1}$ Center for Behavior, Evolution, and Culture, Department of Anthropology, UCLA

${ }^{2}$ Behavioural Science Institute, Radboud University Nijmegen

\begin{abstract}
Research has shown that male risk taking is enhanced by the presence of observers. However, naturalistic observations and laboratory experiments have provided mixed evidence as to whether male physical risk taking is primarily directed at females, at other males, or both. We present a behavioral experiment in virtual reality in which males $(N=72)$ crossed an ominous bridge over a steep valley - either in the presence of a male virtual observer, a female virtual observer, or alone. A male or female experimenter was present while the participants crossed the bridge. Our results show that males crossed the bridge faster in the presence of a female experimenter than in the presence of a male experimenter. Follow up tests revealed that the experimenter effect was driven by the condition in which the virtual observer was female. This finding is consistent with previous work suggesting that male physical risk taking is primarily directed at females.
\end{abstract}

Keywords: physical risk taking, virtual environment, parental investment theory

\section{INTRODUCTION}

Convergent evidence from biology, psychology, and anthropology, has shown that human males are generally more risk-prone than females (BYRNES, MILLER and SCHAFER 1999), although the pattern varies across ages and contexts (HARRIS, JENKINS and GLASER 2006; KRUGER and NESSE 2006), peaking in young adulthood

\footnotetext{
${ }^{*}$ Corresponding author: Willem E. FranKenhuis, Center for Behavior, Evolution, and Culture, Department of Anthropology, UCLA, 341 Haines Hall, Box 951553, Los Angeles, CA, 90095-1553, USA; E-mail: wfrankenhuis@gmail.com
} 
(WILSON and DALY 1985). One influential framework for interpreting this sex difference has been provided by parental investment theory (BATEMAN 1948; TRIVERS 1972), which states that in sexually reproducing species, the sex that invests the most in offspring will be the limiting factor in reproduction, and hence the object of relatively intense competition by the other sex. In humans, like other mammals, females have higher obligate investment per offspring (due to larger gamete size, gestation, lactation and other postnatal care), and thus males may have evolved to be more competitive than females (e.g. ALLMAN et al. 1998).

While research shows that males are more risk taking than females (e.g. BYRNES, MILLER and SCHAFER 1999; DALY and WILSON 2001), many questions remain about the factors and contexts that moderate male risk taking. One idea in evolutionary social science is that male risk taking in part serves communicative functions. In particular, it has been proposed that male risk taking signals underlying fitness-relevant attributes that would otherwise remain opaque to conspecifics, such as physical prowess, skill, bravery, and wealth (e.g. HAWKES 1991; ZAHAVI and ZAHAVI 1997; MiLler 2000; BLIEGE BIRD, SMITH and BIRD 2001; HAWKES and BLIEGE BIRD 2002; WILSON, DALY and POUND 2002). A complete demonstration of signaling requires evidence of a latent variable that varies across individuals, which is fitness-relevant to receivers, and which is communicated through a message that actually correlates with the latent variable (for a thorough treatment of signaling, see MAYNARD SMITH and HARPER 2003). While most studies on signaling in humans have not been able to provide evidence for all of these factors, the signaling hypothesis has led to a productive line of research exploring the ways in which male risk taking is moderated by psychological state (e.g. romantic interest) and context, such as the presence of other individuals (i.e. observers).

We believe it is not always easy to predict from evolutionary principles to whom risk taking should be directed. First, males may benefit from displaying their attributes to both male and female observers, albeit for different reasons - for example, bravery may enhance a male's value as a coalition partner for males, but it might also lead to resources that could benefit a female and her offspring (KELLY and DUNBAR 2001). A second complication is that "risk taking" is not a single behavior, but instead a class of behaviors, some of which may be directed at males and others at females. Studies have shown that even within a given individual, risk taking proclivities tend to vary (i.e. are uncorrelated) across different behavioral domains, such as physical-, financial-, and social risk taking (BLAIS and WEBER 2001; WEBER, BLAIS and BETZ 2002; HANOCH, JOHNSON and WILKE 2006; WILKE et al. 2006). Third, risk taking varies as a function of life history parameters (WANG, KRUGER and WILKE 2009; FeSSLER in press), such as life expectancy (BREZINA, TEKIN and TOPALLI 2009), marital status (FARRINGTON and WEST 1995; DALY and WILSON 2001) and social position (ERMER, COSMIDES and TOOBY 2008), and therefore individual context matters. In light of these factors, it may not be surprising that empirical work has provided mixed results, with some studies reporting that male risk taking was enhanced by the presence of a female observer, 
and other studies finding that male risk taking was enhanced by the presence of a male observer.

Consistent with male risk taking being directed at females, PAWLOWSKI, ATWAL and DUNBAR (2008) showed that the likelihood a male crosses a busy road is positively affected by the number of female observers, while no such effect occurred for the presence of male observers. Also, RONAY and VON HIPPEL (2010) noted that male skateboarders increase their physical risk taking when viewed by a female observer. WILSON and DALY (2004) reported that males discount the future more (i.e. choosing a smaller sum of money tomorrow rather than a larger sum at a later date) after viewing photographs of attractive women. Similarly, BAKER and MANER (2008) found that males who were seeking a mate, made more risky decisions in a gambling task after viewing pictures of attractive female faces. In a different study, BAKER and MANER (2009) revealed "a strong positive relationship between sexual arousal and risk-taking, but only in men exposed to a romantically available female confederate who purportedly would view their risk-taking performance" (p. 1136). KELLY and DUNBAR (2001) showed that females indeed prefer risk-prone brave males to risk-averse non-brave males, and that males are also aware of this preference. Finally, FARTHING (2005) reported that men overestimate the extent to which females value their engaging in non-heroic risk taking, such as bungee jumping or risky sports.

However, other studies document a different pattern of results, with male physical risk taking being enhanced by the presence of male, but not female, observers. JACKSON and GRAY (1976), for instance, showed that male drivers turned faster on a busy street without a stoplight when they were accompanied by a male passenger compared to when they were alone, while no such effect occurred for females passengers. In a similar vein, NUYTS and VESENTINI (2005) found that the probability that a male driver alone in the car wore a seat belt was $48 \%$ (baseline), but that this probability decreased to $34 \%$ when accompanied by a male passenger. In contrast, when a female passenger accompanied a male driver, the probability of seat belt use by the male driver increased to 59\%. These findings are consistent with the idea that males take physical risks to display to other males.

The above studies need not contradict each other as the propensity for risk taking can be moderated by several factors, and these studies may have been different along some of the relevant dimensions. For instance, NUYTS and VESENTINI's (2005) finding that males are more likely to wear a seatbelt in the presence of a female passenger than alone at first seems hard to reconcile with PAWLOWSKI, ATWAL and DUNBAR's (2008) result that males become more likely to cross a busy road with more female observers. However, the male driver and the female passengers in the former study were likely familiar with each other (as they were in the same car), while the male participant and the female observers in the latter study were not. This difference may be significant because it is possible that female acquaintances (such as mothers, sisters, and girlfriends) encourage males not to take physical risks, because they have a stake in their welfare. Given that subtle differ- 
ences in naturalistic settings may have a moderating effect on risk taking, we believe a complementary contribution can be made by research that explores male risk taking in realistic, but highly controlled settings.

Measuring behavior is a challenge. In the past decades, psychological science has increasingly moved away from behavioral studies to other forms of measurement, such as self-reports, hypothetical scenarios, and questionnaire ratings (BAUMEISTER, VOHS and FUNDER 2007; FURR 2009). BAUMEISTER and colleagues (2007) have argued that behavioral measurement is often more time-consuming, expensive, and harder to control than self-report research, while journals increasingly favor articles containing multiple studies (WEGNER 1992), and as a consequence, researchers tend to resort to self-report methods. They further note this trend is unfortunate because self-reports, while sometimes appropriate (e.g. in the study of emotional experience), are often unreliable as predictors of behavior (NISBETT and WILSON 1977). We agree with these observations, and add that a relatively novel technology - Immersive Virtual Environment Technology - may help to alleviate some of the issues that normally plague behavioral studies.

Immersive Virtual Environment Technology has several important advantages as a research tool. As BLASCOVICH and colleagues (2002) have argued, Immersive Virtual Environment Technology allows for almost complete freedom of movement, while simultaneously obtaining precise and fine-grained measurements of natural, ongoing behavior (see also LOOMIS, BLASCOVICH and BEALL 1999; MCCALL and BLASCOVICH 2009). A second benefit is that Immersive Virtual Environment Technology allows for experimental scenarios that are not feasible outside the laboratory, because they would pose unacceptable risks to subjects. The latter benefit is particularly relevant to research on risk taking. Third, Immersive Virtual Environment Technology permits the manipulation of a single variable while maintaining a high degree of ecological validity. This enables control over variables that may otherwise confound experimental outcomes. In the present work, we used Immersive Virtual Environment Technology to study the level of risk taking that males would exhibit in the presence of a male observer, a female observer, or alone.

We constructed a seven-meter long virtual rope bridge (width 1.2 meter) over a steep, ominous virtual valley (Pictures $l a$ and $1 b$ ). Male proneness to engage in risky physical behavior was measured by the speed with which participants crossed the rope bridge to the other side of the valley. Participants crossed the bridge once, either in the presence of a male virtual observer (Picture 1c), or in the presence of a female virtual observer (Picture 1d), or alone. We expected an enhancing effect of virtual observer on male risk taking, i.e. that males would cross the bridge faster in the presence of a virtual person than they would alone. We were particularly interested in measuring whether male physical risk taking is directed more at male or female observers, given conditions where observers are not able to exert an influence on the male's behavior. Since our study investigated the effects of observers on performance, experimenter sex was included in the design to control for possible experimenter sex effects. 


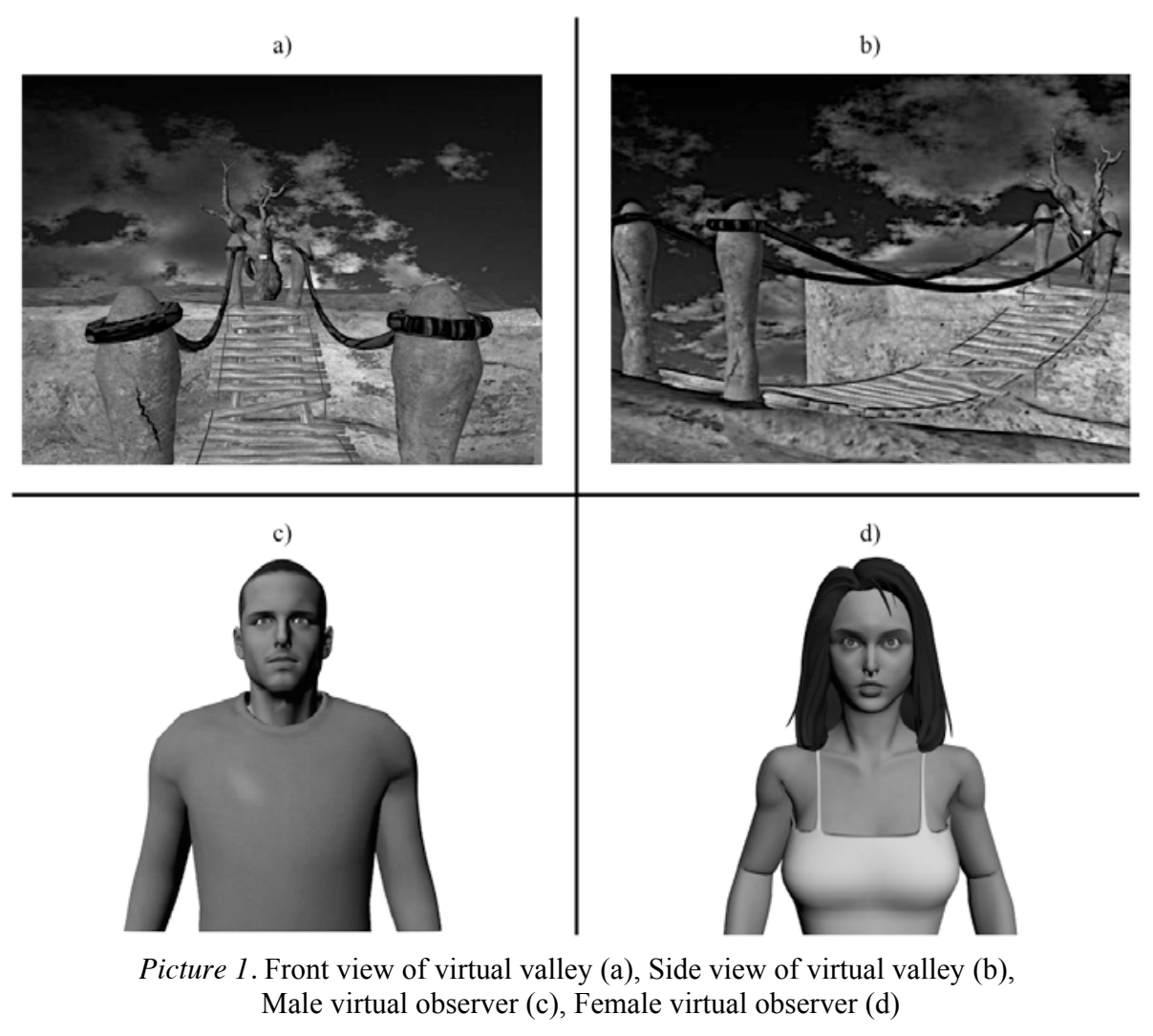

\section{METHODS}

\subsection{Participants}

Eighty-three heterosexual males were recruited as participants. Eleven subjects were excluded from analyses, because of equipment malfunction (2), refusal to cross the bridge out of fear (1) or vertigo (1), experimenter error (2), or mistakes in performance (5), such as deviating from the bridge path before completion or initiating conversation with the experimenter during testing (see also section 2.2 Procedure). Seventy-two males constituted the final sample. Most participants were students of the Radboud University Nijmegen (RU) in the Netherlands. Mean age was 24.1 years $(S D=5.6$ years, range $18-56$ years). All participants signed informed consent forms and stated that they had normal or corrected-to-normal stereoscopic vision, and no extreme fear of heights. Participants were compensated financially or with course credits needed to complete their Bachelors degree. 


\subsection{Procedure}

To become familiar with the experience of navigating in a virtual environment, participants were first immersed in a virtual museum, where they could freely walk around. In actuality, participants were walking in a large room (length 8 meter $\times$ width 4 meter) wearing a virtual reality helmet. The helmet was a stereoscopic head mounted display covering $60^{\circ}$ diagonal field-of-view, which presented the computer-generated environment based on participants' actual position and orientation at $60 \mathrm{~Hz}$.

After participants indicated feeling comfortable traversing the virtual museum, participants were told they would be immersed in a novel virtual environment, where they would read and remember three two-digit numbers. This memorization task was included to distract the subjects from thinking about the aims of the research. The first number would be located either on the chest of a male or female virtual observer, or floating in the air at chest-height (in the alone condition). The second number was located in front of the participant on a virtual twig just below the rope bridge - observing this number would enhance awareness of height. The third number was located on a virtual tree on the other side of the valley, which was located at a distance of seven meters from the participant. In order to reach the tree participants had to cross the bridge to the other side of the valley. To ensure that participants crossed the entire bridge, the third number was initially blurred and became visible only when participants arrived within a distance of 1.5 meters from the tree. Memory performance was not scored.

After participants had received the verbal instructions and any questions had been answered, they completed a practice trial on a virtual sidewalk. This sidewalk served to familiarize participants with the task, and in particular to make sure that all the instructions had been understood. If a participant made an error on the sidewalk (e.g. forgot to look at one of the numbers), the experimenter would point out the mistake to the participant, who then had a chance to correct it. When the sidewalk had been traversed correctly, the bridge trial would start. After the bridge trial begun, the experimenters did not interfere with participants' performance.

\subsection{Experimenters}

Three experimenters facilitated the study: a male experimenter ( 25 years old) tested forty-one participants, and thirty-one participants were tested by one of two female experimenters (mean age is 23.5 years, $S D=1.5$ year). 


\section{RESULTS}

All trips were one-way: from the point where the subject started walking on the bridge, to the point where the subject turned to walk back. Means are reported in meters per second.

A 3 (virtual observer: none vs. male vs. female) $\times 2$ (experimenter sex: male vs. female) ANOVA on speed $(\mathrm{m} / \mathrm{s})$ with all factors as between subjects factors, revealed a main effect for experimenter, $F(1,71)=4.34, p=.04, \eta_{\text {partial }}{ }^{2}=.06$. Participants crossed the bridge faster when the experimenter was female $(M=0.54$, $S E=0.03)$ compared to when the experimenter was male $(M=0.47, S E=0.02)$. The main effect for virtual observer, however, was not significant, $F(1,71)=0.14, n s .{ }^{1}$

Also, the experimenter effect was qualified by a significant interaction between virtual observer and experimenter sex, $F(2,66)=3.08, p=.05, \eta_{\text {partial }}^{2}=.09$. Subsequent pair-wise comparisons showed that only with the female virtual observer, males crossed the bridge faster in the presence of a female experimenter than in the presence of a male experimenter, $F(1,66)=10.15, p=.002$ (Bonferroni-corrected $p=.03), \eta_{\text {partial }}{ }^{2}=.13$. There was no experimenter sex effect either with the male virtual observer, $F(1,66)=0.07, n s$, or with no virtual observer present, $F(1,66)=0.01, n s$. Mean values and standard errors are reported in Table 1.

Table 1. Average crossing speed in $\mathrm{m} / \mathrm{s}$ (meters per second). Values in parentheses represent 1 SEM.

\begin{tabular}{lcl}
\hline \multicolumn{3}{c}{ Experimenter sex } \\
\hline Virtual observer & Male & Female \\
\hline None & $.49(.04)$ & $.50(.05)$ \\
Male & $.50(.04)$ & $.50(.05)$ \\
Female & $.42^{\mathrm{a}}(.04)$ & $.62^{\mathrm{b}}(.05)$ \\
\hline
\end{tabular}

${ }^{\mathrm{a}, \mathrm{b}}$ Means with different subscripts across rows differ significantly $(p<.05)$

\section{DISCUSSION}

Our results indicate that males crossed the bridge faster in the presence of a female experimenter than in the presence of a male experimenter, however, this effect in-

\footnotetext{
${ }^{1}$ Analyses using simpler models yielded the following results. A one-factor (virtual observer: none vs. male vs. female) ANOVA revealed no significant effect, $F(2,69)=0.02, n s$. A $t$-test of the effect of experimenter sex (male vs. both females) replicated the main effect of the $3 \times 2$ ANOVA reported in the Results, $t(70)=2.00, p=.05, d=.46$. There were two female experimenters; $t$-tests comparing each female experimenter separately to the male experimenter showed no significant effects, all $t$ 's $<1.56, n s$. However, with each female experimenter participants crossed the bridge faster $(M=.55, S E=.05, n=17$ and $M=.53, S E=.04, n=14)$ than they did with the male experimenter $(M=.47, S E=.02, n=41)$.
} 
teracted with the virtual observer: specifically, only when the virtual observer was female, males crossed the bridge faster in the presence of a female experimenter than in the presence of a male experimenter. The present findings are therefore generally in line with previous research suggesting that male risk taking is primarily directed at females. We found no evidence that males were more risk-prone in the presence of another male (virtual or actual), or that males were more risk-prone in the presence of an observer, irrespective of sex, compared to when they were alone.

Since we did not predict the interaction effect between virtual and actual observer (i.e. experimenter), it is warranted that we be cautious in our interpretations. It is also important to keep in mind that the experimenter-condition interaction was driven by two results: males crossing the bridge faster in the presence of a female experimenter and a female virtual observer; and, males crossing the bridge slower with a male experimenter and female virtual observer. We begin by discussing the former finding, because it stands out the most in our results (see Table 1).

Research generally shows that male risk taking can be influenced by both situational and psychological context. BAKER and MANER $(2008,2009)$, for instance, have shown that males are more risk-prone when they are in a state of romantic or sexual arousal and believe a romantically available spectator is observing their behavior. The males in our study knew that the experimenter was viewing their performance, because the experimenter remained in the room (for safety reasons) as participants were completing the experiment. When the experimenter was female, our participants may have been motivated to present themselves more favorably (in this case, as more risk taking), especially when they were in an aroused state. This state of arousal may have been elicited by the female virtual observer; if so, the combination of a female experimenter and a female virtual observer could have produced the males' faster crossing of the risky bridge. A related possibility is that the female experimenters initially had an arousing effect on the males, which was then prolonged by the female virtual observer. Both these explanations fit with the hypothesis that male physical risk taking is primarily directed at females and reflects romantic interest.

A second possibility is that males attributed the arousal produced by the bridge to the female virtual person, and as a result perceived the bridge as less frightening. In a classical study, DUTTON and ARON (1974) showed that men who were given a telephone number by an attractive female confederate on a dangerous-looking bridge were more likely to seek post-experimental contact than men who were given a phone number on a safe-looking bridge. DUTTON and ARON (1974) suggested that men might have attributed the arousal produced by the dangerous bridge to the female confederate, making her more attractive and to be pursued through post-experimental contact. The male participants in our study may have attributed the arousal they felt as they crossed the bridge to the female virtual person, which they had viewed from up close (when reading the number located on her chest) as they approached the bridge. This arousal attribution, combined with a motivation to 
impress the female experimenter, may have led them to cross the otherwise dangerous-looking bridge at a relatively faster pace.

A third explanation is that male proneness to risky physical behavior is sensitive to the number of female observers present; the more female spectators, the more reputation benefits a male might reap from a single risky act. This explanation is compatible with the previous explanation, as more female observers may yield greater levels of arousal in males. Under some conditions, one female observer may suffice to elicit enough arousal to produce risk taking (e.g. if the observer is highly desirable). However, at other times males may only be willing to display, or show off more, in the presence of several females. This explanation is consistent with results obtained by PAWLOWSKI and colleagues (2008), who found that males were more likely to cross a busy road as the number of female observers increased. Future studies might explore in more detail how the male propensity to engage in risky behavior is contingent on the number of female observers, their particular features, and group composition in general.

The three explanations provided thus far emphasize that males crossed the bridge relatively fast when both a female virtual observer and a female experimenter were present. However, the experimenter effect is also in part driven by males crossing the bridge relatively more slowly in the presence of a male experimenter and a female virtual observer. We do not know why this the case, but one possibility is that participants perceived the male experimenter as a rival male. If they did, they may have considered him a threat when they were crossing the ominous bridge to the other side of the valley, leading them to cross more cautiously. Another possibility is that participants did not want to compete with the male experimenter over the female virtual observer, and that they communicated this lack of competitive drive by crossing the dangerous bridge in a relatively sensible manner. This explanation raises the question whether males ever use "sensible signals" to communicate a disinterest in competing with other males. Functionally, such "sensible signals" may be likened to subordination behaviors, as the actor is trying to avoid a competitive situation that could otherwise impose costs. However, these ideas remain to be tested before theoretical weight is assigned to them.

To conclude, we used Immersive Virtual Environment Technology to explore observer effects on male physical risk taking. This technology allowed us to obtain fine-grained measurements of natural, ongoing behavior, in a controlled setting that would not have been feasible outside the laboratory, because of the hazards posed to participants (LOOMIS, BLASCOVICH and BEALL 1999; BLASCOVICH 2009; MCCALL and BLASCOVICH 2009). We believe that Immersive Virtual Environment Technology has the potential to become an increasingly important tool in the study of human behavior for two reasons: (1) There appears to be a growing appetite in psychology for the study of "actual" behavior, that is, as opposed to self-reports, hypothetical scenarios, and questionnaire ratings (see BAUMEISTER, VOHS and FUNDER 2007; FURR 2009). Illustrative is the fact that the American Psychological Association (APA) has dubbed the first decade of the twenty-first century The Decade 
of Behavior. Immersive Virtual Environment Technology allows for spontaneous behavior, which can be measured in a reliable and economic way. (2) Psychologists are becoming increasingly interested in dynamic and embodied approaches, focusing on the ways in which the actions of individuals, as embedded in a specific social and physical ecology, shape their cognitive structures (e.g. CLARK 1999). Dynamic and embodied approaches may benefit from using Immersive Virtual Environment Technology, because it enables tracking with great precision not only the position of the entire body, but also of specific body parts and their relation to each other, and crucially, how these interact with features of the environment.

\section{ACKNOWLEDGEMENTS}

We thank the editor Daniel Nettle, two reviewers, Andreas Wilke, Annemie Ploeger, Irene Godoy, Karthik Panchanathan, Maarten Frankenhuis, Philip Lu, and Wouter van den Bos for helpful discussion and comments. We thank Jeroen Derks for modeling the virtual environment. We thank Ellen Cromback and Rianne van Brink for their assistance testing subjects.

\section{REFERENCES}

Allman, J., Rosin, A., Kumar, R. \& Hasenstaub, A. (1998): Parenting and survival in anthropoid primates: Caretakers live longer. Proceedings of the National Academy of Sciences USA, 95, 6866-6869.

BAKER, M. J. \& MANER, J. K. (2008): Risk-taking as a situationally sensitive male mating strategy. Evolution and Human Behavior, 29, 391-395.

BAKER, M. J. \& MANER, J. K. (2009): Male risk-taking as a context-sensitive signaling device. Journal of Experimental Social Psychology, 45, 1136-1139.

BAteman, A. J. (1948): Intra-sexual competition in Drosophila. Heredity, 2, 349-368.

BAumeister, R. F., Vohs, K. D. \& Funder, D. C. (2007): Psychology as the science of selfreports and finger movements. Perspectives on Psychological Science, 2, 396-403.

Blascovich, J., Loomis, J., Beall, A. C., Swinth, K. R., Hoyt, C. L. \& Bailenson, J. N. (2002): Immersive virtual environment technology as a methodological tool for social psychology. Psychological Inquiry, 13, 103-124.

Bliege Bird, R., SMith, E. A. \& BiRD, D. W. (2001): The hunting handicap: Costly signaling in human foraging strategies. Behavioral Ecology and Sociobiology, 50, 9-19.

Blais, A-R. \& WEBER, E. U. (2001): Domain-specificity and gender differences in decision making. Risk, Decision and Policy, 6, 47-69.

BrezinA, T., Tekin, E. \& Topalli, V. (2009): "Might not be a tomorrow": A multimethods approach to anticipated early death and youth crime. Criminology, 47, 1091-1129.

Byrnes, J. P., Miller, D. C. \& Schafer, W. D. (1999): Gender differences in risk taking: A meta-analysis. Psychological Bulletin, 125, 367-383.

Clark, A. (1999): An embodied cognitive science? Trends in Cognitive Sciences, 3, 345-351.

DALY, M. \& WILSON, M. (2001): Risk-taking, intrasexual competition, and homicide. Nebraska Symposium on Motivation, 47, 1-36. 
DutTon, D. G. \& ARON, A. P. (1974): Some evidence for heightened sexual attraction under conditions of high anxiety. Journal of Personality and Social Psychology, 30, 510-517.

ERmer, E., Cosmides, L. \& ToOBY, J. (2008): Relative status regulates risky decision making about resources in men: Evidence for the co-evolution of motivation and cognition. Evolution and Human Behavior, 29, 106-118.

FARRINGTON, D. P. \& WeST, D. J. (1995): Effects of marriage, separation, and children on offending by adult males. Current perspectives on aging and the life cycle, 4, 249-281.

FARTHING, G. W. (2005): Attitudes toward heroic and nonheroic physical risk takers as mates and as friends. Evolution and Human Behavior, 26, 171-185.

FESSLER, D. M. T. (in press): Madmen: An evolutionary perspective on anger and men's violent responses to transgression. In: M. Potegal, G. Stemmler \& C. Spielberger (eds): Handbook of Anger: Constituent and Concomitant Biological, Psychological, and Social Processes.

FURR, R. M. (2009): Personality psychology as a truly behavioural science. European Journal of Psychology, 23, 369-401.

Hanoch, Y., Johnson, J. G. \& Wilke, A. (2006): Domain-specificity in experimental measures and participant recruitment: An application to risk-taking behavior. Psychological Science, 17, 300-304.

HARRIS, C. R., JENKINS, M. \& GlASER, D. (2006): Gender differences in risk assessment: Why do women take fewer risks than men? Judgment and Decision Making, 1, 48-63.

HAWKES, K. (1991): Showing off: Tests of an hypothesis about men's foraging goals. Ethology and Sociobiology, 12, 29-54.

HAwKes, K. \& Bliege Bird, R. (2002): Showing off, handicap signaling, and the evolution of men's work. Evolutionary Anthropology, 11, 58-67.

JACKSON, T. T. \& GRAY, M. (1976): Field study of risk-taking behavior of automobile drivers. Perceptual and Motor Skills, 43, 471-474.

Kelly, S. \& Dunbar, R. I. M. (2001): Who dares, wins: Heroism versus altruism in women's mate choice. Human Nature, 12, 89-105.

Kruger, D. J. \& NesSe, R. M. (2006): An evolutionary life-history framework for understanding sex differences in human mortality rates. Human Nature, 17, 74-97.

LoOMIS, J. M., BlASCOVICH, J. J. \& BeALl, A. C. (1999): Immersive virtual environments as a basic research tool in psychology. Behavior Research Methods, Instruments, and Computers, $31,557-564$.

MAYNARD SMith, J. \& HARPER, D. (2003): Animals signals. Oxford: Oxford University Press.

MCCAll, C. \& Blascovich, J. (2009): How, when, and why to use digital experimental virtual environments to study social behavior. Social and Personality Psychology Compass, 3/5, $744-758$.

Miller, G. F. (2000): The Mating Mind: How Sexual Choice Shaped the Evolution of Human Nature. New York: Doubleday.

NisBetT, R. E. \& WiLSON, T. D. (1977): Telling more than we can know: Verbal reports on mental processes. Psychological Review, 84, 231-259.

NuYTS, E. \& VESENTINI, L. (2005): The relation between seat belt use of drivers and passengers. In: D. de Waard, K.A. Brookhuis, R. van Egmond \& Th. Boersma (eds): Human Factors in Design, Safety, and Management. Maastricht, the Netherlands: Shaker Publishing, pp. 1-11.

Pawlowski, B., ATwal, R. \& DunBaR, R. I. M. (2008): Sex differences in everyday risk-taking behavior in humans. Evolutionary Psychology, 6, 29-42.

RONAY, R. \& VON HIPPEL, W. (2010). The presence of an attractive woman elevates testosterone and physical risk taking in young men. Social Psychological and Personality Science, 1, 57-64.

SMith, E. A. \& BiRD, R. L. B. (2000): Turtle hunting and tombstone opening: Public generosity as costly signaling. Evolution and Human Behavior, 21, 223-244. 
TrIVERS, R. L. (1972): Parental investment and sexual selection. In: B. Campbell (ed.): Sexual Selection and the Descent of Man: 1871-1971. Chicago: Aldine, pp. 136-179.

WANG, X. T., KRUger, D. J. \& WiLKe, A. (2009): Life history variables and risk-taking propensity. Evolution and Human Behavior, 30, 77-84.

Weber, E. U., Blais, A-R. \& Betz, N. E. (2002): A domain-specific risk-attitude scale: Measuring risk perceptions and risk behaviors. Journal of Behavioral Decision Making, 15, 263290.

Wegner, D. M (1992): The premature demise of the solo experiment. Personality and Social Psychology Bulletin, 18, 504-508.

Wilke, A., Hutchinson, J. M. C., TodD, P. M. \& KRUger, D. J. (2006): Is risk taking used as a cue in mate choice? Evolutionary Psychology, 4, 367-393.

Wilson, M. \& DALY, M. (1985): Competitiveness, risk taking, and violence: The young male syndrome. Ethology and Sociobiology, 6, 59-73.

Wilson, M. \& DALY, M. (2004): Do pretty women inspire men to discount the future? Biology Letters, 271, S177-S179.

Wilson, M., DALY, M. \& Pound, N. (2002): An evolutionary psychological perspective on the modulation of competitive confrontation and risk-taking. In: D. Pfaff et al. (eds): Hormones, Brain and Behavior, Vol.5. San Diego: Academic Press, pp. 381-408.

Zahavi, A. \& ZAhavi, A. (1997): The Handicap Principle: A Missing Piece of Darwin's Puzzle. New York: Oxford University Press. 